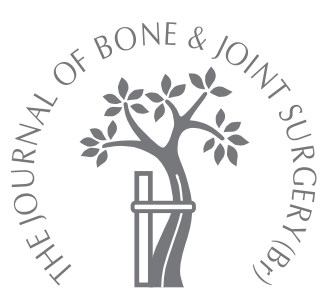

P.-A. Vendittoli, M. Lavigne, J. Girard, A. G. Roy

From Hôpital MaisonneuveRosemont, Montréal, Canada

\title{
A randomised study comparing resection of acetabular bone at resurfacing and total hip replacement
}

\author{
We have undertaken a prospective, randomised study to compare conservation of \\ acetabular bone after total hip replacement and resurfacing arthroplasty of the hip. We \\ randomly assigned 210 hips to one of the two treatment groups. Uncemented, press-fit \\ acetabular components were used for both. \\ No significant difference was found in the mean diameter of acetabular implant inserted \\ in the groups $\mathbf{5 4 . 7 4} \mathbf{~ m m}$ for total hip replacement and $\mathbf{5 4 . 9 0} \mathbf{~ m m}$ for resurfacing \\ arthroplasty). In seven resurfacing procedures $(6.8 \%)$, the surgeon used a larger size of \\ component in order to match the corresponding diameter of the femoral component. \\ With resurfacing arthroplasty, conservation of bone is clearly advantageous on the \\ femoral side. Our study has shown that, with a specific design of acetabular implant and by \\ following a careful surgical technique, removal of bone on the acetabular side is \\ comparable with that of total hip replacement.
}

Although total hip replacement (THR) has a satisfactory clinical outcome in older patients, failure as high as $33 \%$ has been recorded by the Swedish Registry ${ }^{1}$ at 16 years for men aged less than 55 years. The management of bone defects at revision surgery can be challenging and may influence the clinical outcome. In young and active adults, all efforts should be made to minimise the loss of femoral and acetabular bone during the initial arthroplasty.

With a better understanding of the mechanisms of failure of resurfacing arthroplasty and the improved quality of metal-on-metal bearing surfaces, this procedure has gained in popularity. ${ }^{2,3}$ A prospective, randomised study is necessary in order to appreciate the different performances of THR and resurfacing arthroplasty ${ }^{4}$ in regard to restoration of the biomechanics, clinical function, associated complications, preservation of bone and survivorship of the implant. We undertook such an investigation in 2003 and the outcomes regarding restoration of the biomechanics and early clinical results by both procedures have already been published. ${ }^{5}$

Compared with THR, resurfacing arthroplasty preserves more proximal femoral bone stock, thereby allowing easier revision on the femoral side when needed. ${ }^{6}$ On the acetabular side, the preservation of bone stock after resurfacing compared with THR has not been assessed. We therefore compared the sizes of the acetabular component used in a randomised, controlled trial of metal-on-metal THR and resurfacing arthroplasty.

\section{Patients and Methods}

Between July 2003 and December 2005, 194 patients (210 hips) aged between 18 and 65 years with degenerative disease of the hip were randomly assigned to a THR group (103) and to a resurfacing arthroplasty group (107). Bilateral procedures were performed in 16 patients, seven bilateral THRs, three with resurfacing arthroplasty and THR, and six with bilateral resurfacing arthroplasties. The clinical details were comparable between the two groups except for BMI (Table I). The procedures were carried out by three orthopaedic surgeons (P-AV, ML, AGR) working in the same institution. Exclusion criteria included: hip arthrodesis, renal insufficiency, known or suspected metal allergy and osteopenia or osteoporosis of the hip. The protocol was approved by the research ethics and scientific evaluation committees of our institution. All patients who participated in the study gave written informed consent. For each surgeon a block randomisation table was created using SPSS version 10.04 software (SPSS Inc., Chicago, Illinois).

Operative technique. The patients were placed in the lateral decubitus position and a posterior approach was used in both groups. In the THR 
Table I. Clinical details and pre-operative diagnoses for both groups

\begin{tabular}{|c|c|c|c|}
\hline & $\begin{array}{l}\text { Resurfacing arthroplasty } \\
(\mathrm{n}=107)\end{array}$ & $\operatorname{THR}^{*}(\mathrm{n}=103)$ & p value \\
\hline Number of men (\%) & $67(63)$ & $70(68)$ & \\
\hline Number of women (\%) & $40(37)$ & 33 (32) & 0.416 \\
\hline \multicolumn{4}{|l|}{ Age at time of surgery (yrs) } \\
\hline Mean (SD; range) & $49.1(8.8 ; 23$ to 64$)$ & $50.6(8.6 ; 24$ to 65$)$ & 0.199 \\
\hline Median & 51 & 51 & \\
\hline \multicolumn{4}{|l|}{ Side } \\
\hline Right & 51 & 51 & 0.845 \\
\hline Left & 56 & 52 & \\
\hline Mean height in $\mathrm{cm}$ (SD; range) & $172(10.0 ; 151$ to 192$)$ & $172(10.0 ; 150$ to 195$)$ & 0.999 \\
\hline Mean $\mathrm{BMI}^{\dagger}$ (SD; range) & $27.2(5.6 ; 17.6$ to 44.9$)$ & $29.6(6.3 ; 17.4$ to 49.1$)$ & 0.01 \\
\hline Pre-operative diagnosis (number of patients) & & & 0.152 \\
\hline Osteoarthritis & 81 & 78 & \\
\hline Impinging hip & 45 & 32 & \\
\hline Idiopathic & 31 & 39 & \\
\hline Protrusio & 5 & 7 & \\
\hline Childhood diseases & 13 & 10 & \\
\hline Perthes' & 3 & 3 & \\
\hline Dysplasia (Crowe I) & 6 & 5 & \\
\hline Dysplasia (Crowe II) & 4 & 2 & \\
\hline Inflammatory arthritis & 5 & 11 & \\
\hline Rheumatoid arthritis & 4 & 9 & \\
\hline Ankylosing spondylitis & 1 & 2 & \\
\hline Osteonecrosis & 3 & 2 & \\
\hline Post-traumatic arthritis & 3 & 2 & \\
\hline Post-septic arthritis & 2 & 0 & \\
\hline
\end{tabular}

group, a CLS Spotorno (Zimmer, Warsaw, Indiana) titanium uncemented femoral component, an Allofit (Zimmer) uncemented acetabular shell (Fig. 1), a Metasul (Zimmer) high-carbon cobalt-chrome polyethylene sandwich acetabular insert and a $28 \mathrm{~mm}$ femoral head (Zimmer) were used. The Allofit acetabular component has a flattened pole and

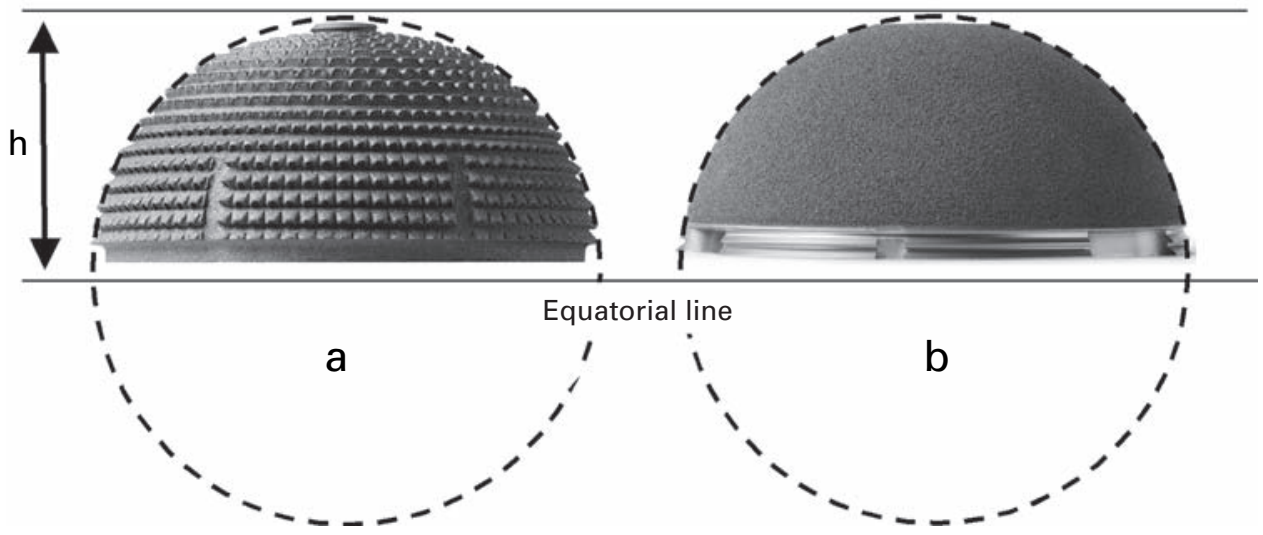

Fig. 1

Diagrams showing a) the Allofit (Zimmer) acetabular component with a double radius design and a flattened pole and b) the Durom (Zimmer) acetabular component with a spherical shape, an arc of $165^{\circ}$ and a flattened pole. Both components have a height $(h$ ) difference within $1 \mathrm{~mm}$ of each other (for component diameters of 48 $\mathrm{mm}$ to $62 \mathrm{~mm}$ ). 
an expanded rim and does not represent a full hemisphere. It has a titanium grit-blasted surface with $1 \mathrm{~mm}$ forged Ridgelock macrotexture (Zimmer), providing a total wall thickness of $2.9 \mathrm{~mm}$. It is available with or without screw holes. The manufacturer recommends insertion with a $2 \mathrm{~mm}$ press-fit.

In the resurfacing arthroplasty group, the hybrid Durom (Zimmer) resurfacing system with a cemented high-carbon cobalt-chrome femoral component (1 $\mathrm{mm}$ cement mantle) and a cobalt-chrome uncemented acetabular component with a $250 \mu \mathrm{m}$ titanium vacuum plasma-sprayed coating were used (Fig. 1). The femoral and acetabular components are available in size increments of $2 \mathrm{~mm}$. The acetabular component is a reduced hemisphere with a flattened pole and subtends an angle of $165^{\circ}$. The manufacturer recommends insertion with $2 \mathrm{~mm}$ of press-fit. An additional $1 \mathrm{~mm}$ of press-fit is given at the equator by engagement of the peripheral fin. The wall has a constant thickness of $4 \mathrm{~mm}$. The acetabular component matches the femoral component, which is $8 \mathrm{~mm}$ smaller in diameter. Even if the design of the acetabular component differs for the same diameter, the heights of both components are within $1 \mathrm{~mm}$ of each other (Fig. 1).

The same surgical technique was used in both groups. During preparation of the acetabulum, careful reaming was carried out in order to obtain a bleeding surface, without necessarily aiming to ream down to the acetabular fossa. The reaming technique was independent of the presence or absence of a central osteophyte. When present this increased the surface area for fixation. When absent, the residual fossa was grafted with products of reaming at the surgeon's discretion. The prepared surface area for fixation was assessed with a trial component in place and bleeding was judged acceptable and sufficient if at least pin-point bleeding was obtained. If the acetabular subchondral bone showed insufficient bleeding in small areas after achieving a spherical cavity of sufficient depth to contain the trial component, a sharp osteotome was used to create microfractures and bleeding instead of enlarging the acetabular cavity and removing more subchondral bone. Peripheral osteophytes were removed with the final component in place in order to ensure that the bony rim of the acetabulum was flush with the component.

The same acetabular reamers were used for both groups. The nominal size of the acetabular components for both THR and resurfacing arthroplasty is based on the true diameter of the corresponding reamer. Intra-operatively, the size of the last reamer used was recorded. In the resurfacing group, if the surgeon thought that acetabular preparation was optimal for implantation, but required oversizing to match the selected femoral component, this was recorded. The intra-operative stability of the acetabular component was classified as excellent, good or unsatisfactory. Screw fixation was undertaken during THR at the surgeon's discretion if the stability of the press-fit was considered to be insufficient. Since no screws can be used with the
Durom acetabular component, a larger version was used, with or without further reaming, when unsatisfactory fixation occurred.

\section{Operative technique and acetabular preparation in specific disorders}

Osteoarthritis secondary to femoroacetabular impingement. There is reduced concavity of the anterior femoral neck with apparent retroversion of the femoral head, wear of the anterosuperior femoral head and a reduced anterior femoral head offset. ${ }^{7}$ In some cases, lateral subluxation of the head with secondary widening of the medial part of the neck because of changes in load transmission is seen, along with obliteration of the acetabular fossa by osteophytes. The ratio of the head/neck diameter is reduced because of the wider femoral neck and the acetabulum is thus relatively small. In these cases, the size of the acetabular component was dictated by the diameter of the femoral neck. During surgery, the surgeon measures the least inferior-tosuperior neck diameter, and then reams the acetabulum up to the corresponding acetabular component diameter. This is usually sufficient to achieve stability of the component and bleeding bone. The femoral head is then prepared by sequential reaming, beginning two sizes larger. Before downsizing to the next reamer, the surgeon assesses the head-neck junction in order to assess the residual bone in the head before reaching the neck. If there is a risk of notching, the surgeon stops reaming the femoral head and returns to the acetabular side in order to increase the acetabular diameter to match the last size of the femoral reamer. Inflammatory arthritis of the hip. Erosion, with enlargement of the acetabulum and an absence of osteophytes on a small femoral head and neck, may result in a mismatch in size between the femoral and acetabular components. Minimal acetabular reaming to obtain peripheral bleeding of bone and to avoid unnecessary medialisation of the acetabular component, optimises conservation of bone and avoids mismatch of the components. Providing that the primary stability of the acetabular component is satisfactory, the gap between the dome of the component and the medial wall because of incomplete seating is either filled with morsellised bone from reaming, or left alone. After the smallest acetabular component has been inserted, the femoral head is prepared with little risk of notching, because of a large diameter ratio.

Avascular necrosis of the femoral head. The femur is characterised by a normal head and neck diameter ratio with no femoroacetabular size mismatch. The main concern is to reduce the size of the necrotic area in the head in order to improve support. Depending upon the location and size of the necrotic lesion, the surgeon tries to reduce the size of the head, shorten it, or translate the component appropriately. Once the acetabular component has been securely fixed, the surgeon prepares the femur and selects the best position which will diminish the size of the necrotic lesion.

Acetabular dysplasia. This usually favours a large headneck offset and a high femoroacetabular diameter ratio. 
Table II. Diameter and stability of the acetabular component for both groups by number $(\%)$

\begin{tabular}{|c|c|c|c|}
\hline & $\begin{array}{l}\text { Resurfacing } \\
\text { arthroplasty } \\
(\mathrm{n}=103)\end{array}$ & $\operatorname{THR}^{*}(n=102)$ & $p$ value \\
\hline \multicolumn{4}{|c|}{$\begin{array}{l}\text { Acetabular under-reaming } \\
(\mathrm{mm})\end{array}$} \\
\hline 1 & $5(4.9)$ & 0 & 0.027 \\
\hline 2 & $98(95)$ & 102 & \\
\hline \multicolumn{4}{|c|}{$\begin{array}{l}\text { Stability of the acetabular } \\
\text { component }\end{array}$} \\
\hline Excellent & $98(95)$ & 89 (87.3) & 0.339 \\
\hline Good & $5(4.9)$ & $13(12.7)$ & \\
\hline Insufficient & 0 & 0 & \\
\hline \multicolumn{4}{|c|}{$\begin{array}{l}\text { Size of acetabular component } \\
(\mathrm{mm})\end{array}$} \\
\hline Mean (SD; range) & $\begin{array}{l}54.90 \\
(3.9 ; 44 \text { to } 64)\end{array}$ & $\begin{array}{l}54.74 \\
(3.5 ; 48 \text { to } 62)\end{array}$ & 0.770 \\
\hline Median & 56 & 56 & \\
\hline
\end{tabular}

* THR, total hip replacement

The limiting factor is the capacity of the surgeon to fix the smallest acetabular component securely without supplementary screw fixation. The degree of acetabular dysplasia dictates the amount of resection of bone needed to obtain satisfactory fixation. In mild acetabular dysplasia, superior 'uncover' of the component may be accepted, provided good primary stability is achieved from anteroposterior engagement of the rim fins in bone. In more severe cases, medialisation of the component is usually necessary. However, the amount of medial bone resection can be reduced by positioning the acetabular component in greater abduction. Once the smallest acetabular component has been inserted, the femoral head is prepared safely with a minimal risk of notching because the ratio of femoral head-neck diameter is large.

Radiological analysis. The patient's diagnosis was classified with consensus by the three surgeons on the basis of the clinical history, available laboratory tests and radiographs. In order to differentiate the hip impingement subgroup, lateral radiographs of the hip were examined carefully as described by Notzli et al. ${ }^{8}$ Acetabular dysplasia was diagnosed with an acetabular index of $>12^{\circ}, 9,10$ and a centreedge angle of Wiberg ${ }^{11}$ of $<20^{\circ}$. Cases of dysplasia were subdivided according to the classification by Crowe, Mani and Ranawat. ${ }^{12}$

Statistical analysis. Student's $t$-test and the chi-squared test were used for continuous and categorical variables, respectively. Continuous variables are presented as the mean (SD) and categorical variables as frequency and percentage. Analyses were performed by SPSS 10.04 software. The degree of significance was defined as $p<0.05$.

\section{Results}

Four hips in the resurfacing arthroplasty group were excluded from the study after intra-operative conversion to a stemmed, large-diameter femoral head arthroplasty. One had extensive necrosis of the femoral head which would have compromised fixation of the component and another had severe retroversion of the femoral neck which was unsuitable for anatomical reconstruction by resurfacing arthroplasty. The third had a severely dysplastic acetabulum which prevented fixation of the component without screws and the fourth had an acetabular diameter of 70 $\mathrm{mm}$; the largest size of Durom resurfacing arthroplasty component available was $66 \mathrm{~mm}$. In one THR patient, the surgeon considered that the quality and shape of the femoral bone were unsuitable for cementless fixation, and the patient therefore received a cemented femoral component and was excluded from the study.

Notching of the femoral neck occurred in nine resurfacing arthroplasties (9\%), in six of $\leq 1 \mathrm{~mm}$, in two of $2 \mathrm{~mm}$ and one of $3 \mathrm{~mm}$. Most notches were in either remodelled bone of the femoral neck or osteophytes. Eight were located anterosuperiorly and one posteriorly. However, no fractures of the femoral neck occurred in the resurfacing arthroplasty group although there were two uneventful acetabular fissures which occurred during impaction of the acetabular component. In order to reduce the risk of acetabular fissure in the acetabulum of less than $50 \mathrm{~mm}$ in diameter, or in very sclerotic bone, under-reaming by $1 \mathrm{~mm}$ was performed in five $(4.9 \%)$ resurfacing arthroplasties. All other resurfacing procedures were under-reamed by $2 \mathrm{~mm}$. In seven $(6.8 \%)$, the surgeon considered that over-sizing the acetabular component by one size $(2 \mathrm{~mm}$ more bone resection) was necessary in order to accommodate the selected femoral component. Intra-operative stability of the acetabular component was classified as excellent in $98(95 \%)$ resurfacing arthroplasties and $89(87.3 \%)$ THRs, and good in five $(4.9 \%)$ resurfacing arthroplasties and $13(12.7 \%)$ THRs $(\mathrm{p}=0.21$, Table II). Supplementary screw fixation was used in five THRs $(5 \%)$. An autologous femoral head served as a bone graft in one patient with acetabular dysplasia in the THR group. One resurfacing arthroplasty in a dysplastic hip (Crowe II) required intra-operative conversion of an unsatisfactorily-fixed acetabular component to a THR in order to improve fixation.

No significant difference was found between the groups in the mean or median diameters of the last reamer used or the mean size of the acetabular component $(54.90 \mathrm{~mm}(44$ to 64) for resurfacing arthroplasty and $54.74 \mathrm{~mm} \mathrm{(48} \mathrm{to}$ 62) for THR, $p=0.770$, Table II). No significant difference in the size of the acetabular component was noted between the groups of the three individual surgeons $(\mathrm{p}=0.89)$. The size of the acetabular component was significantly larger for men in both groups $(p<0.0001)$ and correlated significantly with the body mass index $(p=0.016$; Table I). It did not differ for each diagnosis, particularly for the impinging hip deformity $(p=0.26)$. Three patients were randomised for both hips in different groups, with a resurfacing arthroplasty on one side and a THR on the other. In two patients with symmetrical involvement of the hip, the size of the 
resurfacing arthroplasty and THR acetabular components was the same (bilateral $50 \mathrm{~mm}$ and $56 \mathrm{~mm}$, respectively). In the third patient, the size of the THR acetabular component was greater than that of resurfacing arthroplasty because of an enlarged acetabular cavity secondary to developmental dysplasia of the hip.

\section{Discussion}

Conservation of bone during THR in young patients is critical. With a resurfacing arthroplasty, bone is conserved on the femoral side and after surgery since the density of bone in the femoral neck has been shown to increase post-operatively because of physiological loading and optimal remodelling afforded by the femoral component. ${ }^{13}$ Conservation of bone on the femoral side of a resurfacing arthroplasty makes conversion to a conventional primary THR easier if failure of the femoral component occurs. ${ }^{3,14}$

The degree of preservation of bone on the acetabular side of a resurfacing arthroplasty is less clear.

With first-generation resurfacing components using a cemented polyethylene shell, more reaming of the acetabular bone was necessary to accept the cement mantle and a sufficiently thick component. ${ }^{14}$ With the new generation of metal-on-metal resurfacing arthroplasties, Loughead et $\mathrm{al}^{15}$ analysed a consecutive series of 35 Birmingham hip resurfacings (BHR, Smith and Nephew, Memphis, Tennessee) and 34 hybrid THRs, both with uncemented acetabular components. The sizes of the implanted acetabular component were compared after correction for patient size, using the diameter of the femoral head of the contralateral, normal side. The ratio of acetabular size to the diameter of the contralateral head was 1.18 and 1.14 in the resurfacing arthroplasty and THR groups, respectively $(\mathrm{p}=0.003)$, with a mean size of the acetabular component of $56.4 \mathrm{~mm}$ and $52 \mathrm{~mm}$, respectively, underlining the difference in the clinical details between the groups. The diameter of the femoral head was $48.0 \mathrm{~mm}$ and $45.8 \mathrm{~mm}$ for the resurfacing arthroplasty and THR groups, respectively. This study may be biased by its retrospective nature and by the selection of patients for resurfacing arthroplasty which included more men and different femoral pathoanatomy.

We have shown that conservation of acetabular bone stock in resurfacing arthroplasty can be similar to that in THR. The mean diameter of the acetabular component at resurfacing arthroplasty was no different from that of THR (54.90 vs $54.74, \mathrm{p}=0.770)$. In only seven $(6.8 \%)$ of our resurfacing arthroplasties did the surgeon feel that oversizing the acetabular component was needed to match the femoral component selected according to the diameter of the femoral neck. Because of the stiffness of the acetabular component in resurfacing arthroplasty (forged cobaltchrome with a $4 \mathrm{~mm}$ thick wall) and the presence of a supplementary press-fit of $1 \mathrm{~mm}$ with fin engagement (total of $3 \mathrm{~mm}$ of press-fit), it was decided to under-ream by only 1 $\mathrm{mm}$ when the component used was less than $50 \mathrm{~mm}$ in diameter or when the bone was very sclerotic $(4.9 \%$, five hips). This was not needed with the more flexible THR acetabular component (titanium with a $2.9 \mathrm{~mm}$ thick wall). Therefore, in only $12(12 \%)$ resurfacing arthroplasty procedures was the increase in resection of acetabular bone directly related to the technique ( $1 \mathrm{~mm}$ or $2 \mathrm{~mm}$ more).

In contrast to the study of Loughead et al ${ }^{15}$ our patients were randomised, avoiding selection bias. The surgical technique and position of the implant were similar for the three surgeons involved. We found no significant difference in the size of the acetabular component chosen by each of the three surgeons. In order to ensure that we did not change our surgical technique with our THR group, we reviewed the acetabular component sizes (Allofit, Zimmer) of 54 consecutive patients ( 28 men, 26 women) aged less than 65 years who had a cementless metal-on-metal THR before the start of this study for various disorders. Although the higher male-to-female ratio in our current prospective study should have favoured the use of a larger acetabular component (Table I), the overall mean size of acetabular component in the retrospective series was 54.3 $\mathrm{mm}$, which was similar to that of the THR group in our randomised study $(54.7 \mathrm{~mm})$.

Factors which may influence the amount of acetabular bone resected include the incremental size of implants available, the design of the femoral and acetabular components, and the surgical technique. Increments in size and the range of components available are important factors when upsizing the femoral component in order to avoid notching of the femoral neck, or to improve the head and neck diameter ratio. The larger the increment between sizes of femoral component, the more bone will be sacrificed on the acetabular side. Since the BHR femoral components are available in increments of $4 \mathrm{~mm}$, this may be partly why Loughead et $\mathrm{al}^{15}$ implanted larger acetabular components in their resurfacing arthroplasty group in comparison with their patients undergoing THR. ${ }^{16}$

The design of the femoral component in resurfacing arthroplasty may also influence the resection of acetabular bone stock. For an identical diameter of the femoral head, a thicker implant and the presence of a cement mantle may force the surgeon to use a larger femoral component in order to avoid notching the neck. However, using a thin component without a cement mantle may reduce the postoperative range of movement and may cause impingement because of the reduced head-neck offset. The different femoral implants on the market present different thicknesses of metal and cement mantle. On the pelvic side, the normal acetabulum subtends a mean angle of $158^{\circ}\left(145^{\circ}\right.$ to $\left.173^{\circ}\right) .^{17}$ A completely hemispherical acetabular component such as the BHR, in comparison with one which is less than hemispherical, as used in our study, presents an increased height of the component and requires deeper reaming in order to be fully inserted into a normal acetabulum, therefore increasing bone loss. Although the two components used in our study were not of the same design, both had a similar component height (Fig. 1). The shape of the Durom compo- 
nent for resurfacing arthroplasty represents an arc of a circle of $165^{\circ}$, allowing medial acetabular bone preservation. The THR component (Allofit; Zimmer) comprises two radii, allows conservative acetabular reaming and, when fully seated, has rim fixation. In addition, the presence of a flattened pole in the Durom implant may allow some regeneration of bone, which is advantageous. The thickness of the wall of the acetabular component is also important for bone conservation. For the same size of femoral component, the thicker acetabular implant requires the removal of more bone. However, in a resurfacing arthroplasty which uses very small component clearance, reducing the thickness of the wall by too much increases both the risk of component deformation under load and clamping, thereby limiting the minimum wall thickness to approximately $4 \mathrm{~mm} .{ }^{18} \mathrm{An}$ experimental study of implantation of an acetabular component in dry bones and comparison of the amount of resected bone before implanting a BHR acetabular component with a Press-Fit Condylar acetabular component (PFC, Depuy, Leeds, United Kingdom $)^{19}$ revealed that $311 \%$ more bone had to be removed on the acetabular side with the BHR (5.6 vs $1.8 \mathrm{~g}, \mathrm{p}<0.001)$. Despite the scientific limitations of this study with a dry bone model, design factors and surgical technique were found to be significant.

The increased stiffness of the thicker cobalt-chrome acetabular component of a resurfacing arthroplasty used in our study makes it more difficult to insert in denser sclerotic bone. Over-reaming by $1 \mathrm{~mm}$ was necessary in $4.9 \%$ of hips with resurfacing arthroplasty for acetabular component sizes $<50 \mathrm{~mm}$ or in very sclerotic bone in order to allow insertion of the component, which contributed to increased bone loss.

By carefully following the surgical procedure described, conservation of bone is possible with a resurfacing arthroplasty while maintaining a good range of movement. Minimal reaming to obtain bleeding bone, and preservation of the medial acetabular bone, are critical. A balance between the restoration of range of movement and conservation of acetabular bone should be respected. The range of movement depends on the position of the implant and on restoration of the normal anatomy to the femoral head and neck. Restoration of circumferential head/neck offset will optimise the range of movement in resurfacing arthroplasty. By using a larger femoral component, a better range of movement will be achieved, with less risk of impingement of the neck on the acetabular rim, albeit at the expense of the removal of more acetabular bone. When selecting the smallest femoral component which will fit on the femoral neck without notching, the range of movement is reduced while more acetabular bone stock is preserved. Therefore, the best compromise between restoration of normal movement and conservation of acetabular bone in resurfacing arthroplasty is achieved with a design of femoral component which allows restoration of a normal head/neck offset ratio and an anatomical acetabular design of component (less than $180^{\circ}$ ) with optimal thickness of the wall.
If resurfacing arthroplasty is to achieve long-term survivorship comparable with THR, preservation of femoral bone will clearly be a major advantage of the technique. We have shown that in resurfacing arthroplasty, by using a specific design of implant with attention to careful surgical technique, resection of bone on the acetabular side is comparable to that in THR. A randomised, controlled trial such as ours is essential to reach this conclusion, since patient selection for resurfacing arthroplasty produces a clear bias toward larger sizes of acetabular component in comparison with that in an unselected group of patients undergoing THR.

\section{Supplementary Material}

A further opinion by Mr David Dunlop is available with the electronic version of this article on our website at www.jbjs.org.uk

No benefits in any form have been received or will be received from a commercial party related directly or indirectly to the subject of this article.

\section{References}

1. Malchau H, Herberts P, Eisler T, Garellick G, Soderman P. The Swedish Total Hip Replacement Register. J Bone Joint Surg [Am]2002;84-A(Suppl 2):2-20.

2. Capello WN, Trancik TM, Misamore G, Eaton R. Analysis of revision surgery of resurfacing hip arthroplasty. Clin Orthop 1982;170:50-5.

3. Beaule PE, Dorey FJ, LeDuff M, Gruen T, Amstutz HC. Risk factors affecting outcome of metal-on-metal surface arthroplasty of the hip. Clin Orthop 2004;418:87-93.

4. Howie DW, McGee MA, Costi K, Graves SE. Metal-on-metal resurfacing versus total hip replacement: the value of a randomized clinical trial. Orthop Clin North Am 2005:36:195-201

5. Girard J, Lavigne M, Vendittoli P, Roy A. Biomechanical reconstruction of the hip joint: a randomised study comparting total hip resurfacing and total hip arthroplasty. J Bone Joint Surg [Br] 2006;88-B:721-6.

6. Beaule PE, Lee JL, Le Duff MJ, Amstutz HC, Ebramzadeh E. Orientation of the femoral component in surface arthroplasty of the hip: a biomechanical and clinical analysis. J Bone Joint Surg [Am] 2004;86-A:2015-21.

7. Ganz R, Parvizi J, Beck M, et al. Femoroacetabular impingement: a cause of osteoarthritis of the hip. Clin Orthop 2003;417:112-20.

8. Notzli HP, Wyss TF, Stoecklin CH, et al. The contour of the femoral head-neck junction as a predictor for the risk of anterior impingement. J Bone Joint Surg $[\mathrm{Br}]$ 2002;84-B:556-60.

9. Murphy SB, Ganz R, Muller ME. The prognosis is untreated dysplasia of the hip: a study of radiographic factors that predict the outcome. J Bone Joint Surg [Am] 1995; 77-A:985-9.

10. Tönnis D. Congenital dysplasia of the hip in children and adults. Berlin: Springer-Verlag, 1987:113-31

11. Wiberg G. Studies on dysplastic acetabula and congenital subluxation of the hip joint: with special reference to the complication of osteoarthritis. Acta Chir Scand 1939;58:7-38.

12. Crowe JF, Mani VJ, Ranawat CS. Total hip replacement in congenital dislocation and dysplasia of the hip. J Bone Joint Surg [Am]1979;61-A:15-23.

13. Martini F, Lebherz C, Mayer F, et al. Precision of the measurements of periprosthetic bone mineral density in hips with a custom-made femoral stem. J Bone Joint Surg [Br] 2000;82-B:1065-71.

14. Thomas BJ, Amstutz HC. Revision surgery for failed surface arthroplasty of the hip. Clin Orthop 1982;170:42-9.

15. Loughead JM, Starks I, Chesney D, et al. Removal of acetabular bone in resurfacing of the hip: a comparison with hybrid total hip arthroplasty. J Bone Joint Surg $[\mathrm{Br}]$ 2006;88-B:31-4.

16. Vendittoli PA, Lavigne M, Roy AG, Girard J. Removal of acetabular bone in resurfacing arthroplasty of the hip. J Bone Joint Surg [Br] 2006;88-B:838-9

17. Thompson MS, Dawson T, Kuiper JH, Northmore-Ball MD, Tanner KE. Acetabular morphology and resurfacing design. J Biomech 2000;33:1645-53.

18. Udofia IJ, Yew A, Jin ZM. Contact mechanics analysis of metal-on-metal hip resurfacing prostheses. Proc Inst Mech Eng [H] 2004;218:293-305.

19. Crawford JR, Palmer SJ, Wimhurst JA, Villar RN. Bone loss at hip resurfacing: a comparison with total hip arthroplasty. Hip Int 2005;15:195-8. 